Article

\title{
Combining Ability and Genetic Components of Yield Characteristics, Dry Matter Content, and Total Carotenoids in Provitamin A Cassava F1 Cross-Progeny
}

\author{
Elizabeth Parkes ${ }^{1}$, Olufemi Aina ${ }^{1}$ (D) Akuwa Kingsley ${ }^{1,2}$, Peter Iluebbey ${ }^{1}$, Moshood Bakare ${ }^{1}$, \\ Afolabi Agbona ${ }^{1}$, Patrick Akpotuzor ${ }^{1}$, Maryke Labuschagne ${ }^{3, *}$ (D) and Peter Kulakow ${ }^{1}$ (D) \\ 1 International Institute of Tropical Agriculture (IITA), Ibadan 200001, Nigeria; e.parkes@cgiar.org (E.P.); \\ f_aina2002@yahoo.com (O.A.); akuwakingsley@gmail.com (A.K.); P.Iluebbey@cgiar.org (P.I.); \\ mab658@cornell.edu (M.B.); a.afolabi@cgiar.org (A.A.); P.Akpotuzor@cgiar.org (P.A.); \\ P.Kulakow@cgiar.org (P.K.) \\ 2 Department of Agronomy, University of Ibadan, Ibadan 200284, Nigeria \\ 3 Department of Plant Sciences, University of the Free State, Bloemfontein 9300, South Africa \\ * Correspondence: labuscm@ufs.ac.za
}

Received: 18 October 2020; Accepted: 20 November 2020; Published: 24 November 2020

\begin{abstract}
Cassava is an important root crop in sub-Saharan Africa, largely cultivated for its starchy edible roots. Biofortified cassava varieties with enhanced provitamin A carotenoid content (PVAC) developed through conventional breeding provide a solution for vitamin A deficiency among vulnerable communities. The aim of this study was to use diallel analysis of six provitamin A cassava genotypes to determine the combining ability, genetic components, heritability, and heterosis of the most important yield characteristics and total carotenoids. Genetic variability for measured characteristics were evident. Fresh root yield was mainly determined by non-additive genetic effects, while dry matter content and total carotenoids were determined by additive effects. Total carotenoids were negatively correlated with fresh root yield, indicating that selection for higher provitamin A content could reduce yield. Mid and higher parent heterosis was seen in some of the crosses for fresh root yield, dry matter content, and total carotenoids. Narrow sense heritability was moderate for fresh root yield and dry matter content, and was high for total carotenoids. This study indicated that yield and dry matter content can be improved in provitamin A cassava but that increased provitamin A content may carry a yield penalty.
\end{abstract}

Keywords: cassava; heterosis; vitamin A; dry matter content; root yield

\section{Introduction}

Cassava (Manihot esculenta Crantz) is a shrubby perennial crop with edible storage roots, widely cultivated in the tropics, and ranked as the third largest source of calories after wheat and rice in the world [1]. Cassava grows best on well-drained light to medium soils, with a $\mathrm{pH}$ of 4.5-7.5. It is well adapted to various environments with low input amendment requirements and can generally withstand biotic and abiotic stress [2,3]. Storage root yield is the key objective of cassava breeding programs and farmers attach the highest importance to good storage root yield with higher dry matter content (DMC) [4-6]. Increasing emphasis is being placed on the nutritional value of cassava. This has led to the breeding of provitamin A cassava, which has more total carotenoids (TCs) than white cassava. Carotenoids are essential due to their conversion to vitamin A. Vitamin A deficiency (VAD) is a major 
global public health challenge, particularly in tropical sub-Saharan Africa [7]. Hence, provitamin A cassava is vital given the status of cassava as a major staple crop in the tropics.

The DMC trait in cassava is a component of storage root yield, a complex quantitatively inherited trait [8]. Knowledge of the mode of inheritance of quantitative characteristics helps breeders to employ suitable breeding strategies for their improvement. The diallel mating design is a popular design employed by cassava breeders to obtain information on the value of the hybrids and parents. It is used to assess the gene action involved in various characteristics [9-14] and in applying appropriate selection procedures. It also helps to understand heterotic patterns of progeny at an early stage of hybridization programs [14]. Genetic variation exists among cassava genotypes for all important characteristics, thus providing an opportunity for exploiting this variation through selection [15]. The predominance of additive gene effects in controlling the expression of DMC has been previously reported [12]. This was confirmed by another study [14] that reported additive gene effects to be double that of non-additive gene action for DMC, while non-additive genetic effects were relatively higher for root yield. The yellow pulp color, indicating beta-carotene in cassava, was found to be controlled by non-additive gene effects [3]. Hybrid vigor for root yield over better-parent values and root yield performance associated with heterosis for yield components has been reported [15], indicating that hybrids can be exploited in heterosis breeding in order to develop superior genotypes. Heritability plays a predictive role in breeding, expressing the reliability of phenotype as a guide to breeding value $[16,17]$. Genetic advance is an important selection parameter that explains the degree of gain obtained in a characteristic under particular selection pressure. High genetic advance coupled with high heritability estimates offers the opportunity to predict the effect of selecting superior genotypes $[18,19]$. This aids breeders in a selection program to identify the best responses based on a given selection intensity, for genetic improvement of characteristics [20].

The objective of this study was to do a diallel analysis of six yellow-fleshed parents to determine the combining ability and gene action controlling the expression for TC, storage root yield, and percentage DMC of storage roots, and to estimate the heterosis relative to the mid parent $(\mathrm{MPH})$ and better parent $(\mathrm{BPH})$ for $\mathrm{TC}$, storage root yield, and percentage DMC of storage roots.

\section{Materials and Methods}

\subsection{Experimental Site}

The experiment was conducted at the International Institute of Tropical Agriculture (IITA), at Ibadan and Ikenne research stations in 2012-2015. Ibadan, Oyo State is located at latitude $7^{\circ} 24^{\prime} \mathrm{N}$, longitude $3^{\circ} 55^{\prime} \mathrm{E}$, and altitude $273 \mathrm{~m}$ above sea level while Ikenne, Ogun State is located on latitude $6^{\circ} 53^{\prime} \mathrm{N}$, longitude $3^{\circ} 42^{\prime} \mathrm{E}$, and altitude $60 \mathrm{~m}$ above sea level. Both locations are in the southern rainforest vegetation belt of Nigeria and are characterized by nitosol soils with an annual rainfall range of about $1200-1515 \mathrm{~mm}$ and temperature range of about $22-32{ }^{\circ} \mathrm{C}$.

\subsection{Experimental Material}

The experimental material comprised of six elite yellow cassava parental genotypes (Table 1) (details provided at https://cassavabase.org/). The genotypes were all IITA material, selected for provitamin A content, early bulking, yield, and yield-related characteristics. The pedigree shows the two parents that were crossed (female to male) to obtain each of these genotypes. All the genotypes were full-sibs except forgenotype IITA-TMS-IBA070337, which is a half-sib with high DMC. The first three genotypes are part of the first group of biofortified cassava varieties released in Nigeria. 
Table 1. Pedigree information of the six parents used in this study.

\begin{tabular}{ccccc}
\hline S/N & Parent & Female & Male & Pedigree \\
\hline 1 & IITA-TMS-IBA011368 & IITA-TMS-IBA940561 & IITA-TMS-IBA940263 & IITA-TMS-IBA940561/ITAA-TMS-IBA940263 \\
\hline 2 & IITA-TMS-IBA011371 & IITA-TMS-IBA940561 & IITA-TMS-IBA940263 & IITA-TMS-IBA940561/ITTA-TMS-IBA940263 \\
\hline 3 & IITA-TMS-IBA011412 & IITA-TMS-IBA950971 & IITA-TMS-IBA940561 & IITA-TMS-IBA950971/IITA-TMS-IBA940561 \\
\hline 4 & IITA-TMS-IBA070337 & IITA-TMS-IBA920429 & & IITA-TMS-IBA920429/ \\
\hline 5 & IITA-TMS-IBA070553 & IITA-TMS-IBA011663 & IITA-TMS-IBA011335 & IITA-TMS-IBA011663/ITTA-TMS-IBA011335 \\
\hline 6 & IITA-TMS-IBA070593 & IITA-TMS-IBA011277 & IITA-TMS-IBA990067 & IITA-TMS-IBA011277/IITA-TMS-IBA990067 \\
\hline
\end{tabular}

\subsection{Generation of $F_{1}$ Progenies}

The six parental genotypes were planted in a $6 \times 6$ half diallel design to generate $15 \mathrm{~F}_{1}$ full-sib families (Table 2) through controlled pollination of immature flowers following standard procedures [4]. $\mathrm{F}_{1}$ botanical seeds were harvested three months after pollination. The seeds were placed in a labeled paper bag and stored for three months to break seed dormancy. Seeds were sown directly into a nursery field at $0.25 \mathrm{~m} \times 1 \mathrm{~m}$ intra- and inter-row spacing in a family row plot that was partitioned into a block ridge $20 \mathrm{~m}$ long and arranged in a serpentine pattern with no replicates. An alley of $1 \mathrm{~m}$ was maintained between families. The resulting $\mathrm{F}_{1}$ seedlings were harvested at 12 months after planting (MAP). Selection of plants from the nursery field trial for inclusion in the clonal evaluation trial was based on the ability of each plant to produce five to six good plant stakes. A total of 1581 healthy $\mathrm{F}_{1}$ plants were selected from the nursery trial and advanced to the clonal trial in the second year. For the clonal trial, the $\mathrm{F}_{1}$ genotypes were cut into stakes of about $20 \mathrm{~cm}$ with approximately four to five nodes and planted at a spacing of $0.5 \mathrm{~m} \times 1 \mathrm{~m}$ arranged in an augmented design with no replicates. Parents and checks were included in the trials. Morphological evaluation was carried out at different growth stages $(1,3,6,9$, and $12 \mathrm{MAP})$. Selection of plants from the clonal trial for inclusion in the preliminary yield trial stage was based on performance of each clone based on a selection index rating that considers four key characteristics (TC, DMC, cassava mosaic disease resistance, and plant architecture). Forty clones per family (for most families) were obtained, but there were cases where some clones failed to develop or died and thus could not be evaluated.

Table 2. Frequency table of the size of each family.

\begin{tabular}{ccc}
\hline S/N & Genotype & N \\
\hline 1 & I011368/I011368 & 4 \\
2 & I011368/I011371 & 28 \\
3 & I011368/I011412 & 80 \\
4 & I011368/I070337 & 42 \\
5 & I011368/I070553 & 32 \\
6 & I011371/I011371 & 4 \\
7 & I011371/I011412 & 64 \\
8 & I011371/I070337 & 42 \\
9 & I011371/I070553 & 56 \\
10 & I011412/I011412 & 4 \\
11 & I011412/I070337 & 28 \\
12 & I070337/I070337 & 4 \\
13 & I070553/I011412 & 40 \\
14 & I070553/I070337 & 42 \\
15 & I070553/I070553 & 4 \\
16 & I070593/I011368 & 66 \\
17 & I070593/I011371 & 62 \\
18 & I070593/I011412 & 83 \\
19 & I070593/I070337 & 52 \\
20 & I070593/I070553 & 42 \\
21 & I070593/I070593 & 6 \\
\hline
\end{tabular}




\subsection{Experimental Design}

The preliminary yield trial was arranged in a randomized complete block design with two replicates. Planting was done in September 2014. A total of 379 clones consisting of the 15 cross progenies with the six parents were included in the respective plots of each replicate. Each plot consisted of a single row of 10 plants for each of the clones. The spacing between plants was $0.8 \mathrm{~m} \times 1 \mathrm{~m}$. The field was kept free of weeds for the duration of the growing cycle and neither fertilizer nor irrigation was applied.

\subsection{Data Collection}

Data were collected at harvest (12 MAP). Eight central plants, excluding the first and last plants in a plot, were assessed for their number of storage roots per plant, root weight $\left(\mathrm{kg} \mathrm{plant}^{-1}\right)$, and total shoot weight $\left(\mathrm{kg} \mathrm{plant}^{-1}\right)$. Storage root yield $\left(\mathrm{t} \mathrm{ha}^{-1}\right)$, DMC $(\%)$, and harvestable index were estimated [21]. Total carotenoids $\left(\mu \mathrm{g} \mathrm{g}^{-1}\right)$ in fresh weight were estimated following the IITA standard laboratory procedure, using the iCheck Device [22].

\subsection{Data Analysis}

The data were analyzed using SAS version 9.3 [23]. Diallel analysis was done following method 2, model 1 of Griffing [24] to determine the combining ability and separate components of genetic variance. The mixed model procedure based on the restricted maximum likelihood (REML) estimation method was fitted to the data, where the replication effect is considered fixed, while parent and cross effects were considered random, to estimate the GCA and SCA variance components, respectively [25].

The distribution of crosses in relation to GCA and SCA effects was determined by denoting significant positive combining ability effects as high, non-significant as average, and significantly negative as low, for fresh root weight, DMC, and TC [15]. The GCA/SCA ratio of mean squares for the studied characteristics was determined to predict the gene effects for a trait $[14,26]$. Baker's prediction ratio [27] was used to determine progeny performance. The closer this ratio is to one, the better the chances of predicting progeny performance based on GCA. A value of less than 1 was taken as predominance of non-additive gene action, and higher than 1 as predominance of additive gene action. Heterosis relative to mid-parent and better parent values were estimated as deviation of the $F_{1}$ value from the mid-parent (MP) and the better-parent (BP) values, respectively [28].

Phenotypic correlations $\left(\mathrm{r}_{\mathrm{P}}\right)$ were estimated for each pair of characteristics as the Pearson product moment correlation coefficient using the CORR procedure of SAS version 9.3 [23]. Genetic correlations $\left(r_{G}\right)$ were estimated as previously described [29].

Estimates of variance components for genotypic and phenotypic variances were determined from the estimated values of the mean squares obtained from the ANOVA [19]. Phenotypic coefficient of variation (PCV) and genotypic coefficient of variation (GCV) were also estimated [30]. PCV and GCV values of more than $20 \%$ were regarded as high, whereas values less than $10 \%$ were considered as low and values between $10 \%$ and $20 \%$ as average [31]. Broad and narrow sense heritability $\left(\mathrm{h}^{2} \mathrm{~b}\right.$ and $\mathrm{h}^{2}$ ) were calculated as the ratio of genotypic variance to the phenotypic variance. The broad sense heritability estimates were classified as low (0-30\%), moderate (30-60\%), and high (60\% and above) [1]. Expected genetic advance with one cycle of selection and expected genetic advance as a percentage of the mean was calculated to compare the extent of predicted genetic advance of different characteristics under selection [32]. Genetic advance as a percent of the population mean was categorized as follows: less than $10 \%$ as low, $10-20 \%$ as moderate, and above $20 \%$ as high.

\section{Results}

\subsection{Analysis of Variance}

Highly significant $(p<0.001)$ genotype effects were observed for all the characteristics (Table 3$)$. Significant SCA mean squares were observed for FYLD and TC. The GCA/SCA ratio was higher 
than unity for DMC (12.46) and TC (1.17) but less than one for FYLD (0.16). In addition, the Baker's prediction ratio was low for FYLD (0.24) but closer to 1 for DMC (0.96) and TC (0.70), respectively.

Table 3. Analysis of variance for the genotypes and for the combining ability of the studied characteristics.

\begin{tabular}{ccccc}
\hline \multirow{2}{*}{ Source } & Df & \multicolumn{3}{c}{ Mean Squares } \\
\cline { 3 - 5 } & & FYLD $\left(\mathbf{t ~ h a}^{\mathbf{- 1}}\right)$ & DMC $(\%)$ & TC $_{\left(\boldsymbol{\mu} \mathbf{g ~ g}^{-\mathbf{1}} \mathbf{~ F r e s h ~ W e i g h t ) ~}\right.}$ \\
\hline Genotype & 20 & $647.99^{* * *}$ & $319.24^{* * *}$ & $30.93^{* * *}$ \\
GCA & 5 & 1.65 & 4.61 & 0.34 \\
SCA & 14 & $10.32 *$ & 0.37 & $0.29^{*}$ \\
Residual & 723 & 113.96 & 39.6 & 3.19 \\
GCA/SCA & - & 0.16 & 12.46 & 1.17 \\
Baker's ratio & - & 0.24 & 0.96 & 0.70 \\
\hline
\end{tabular}

$* \overline{p<0.05 ; * * *} p<0.001$, FYLD = Fresh yield, DMC $=$ Dry matter content, TC = Total carotenoids, GCA = general combining ability, SCA = specific combining ability.

\subsection{Mean Performance of Parents and Their Hybrid Progenies}

Parent IITA-TMS-IBA070337 had the highest mean values for root number, root weight, FYLD, DMC, and harvest index while parent IITA-TMS-IBA070593 had the highest mean value for TC (Table 4). Crosses IITA-TMS-IBA011368/IITA-TMS-IBA070337 had the highest values for root number, root weight, and FYLD while IITA-TMS-IBA011412/IITA-TMS-IBA070337 had the highest value for DMC and harvest index. The highest mean value for TC was recorded in IBA070593/IBA011368. The lowest value for FYLD and DMC was recorded in parent IBA070553, while parent IITA-TMS-IBA070337 recorded the lowest value for TC. For the crosses, IBA011368/IITA-TMS-IBA011371 gave the lowest values for FYLD, while IITA-TMS-IBA070553/IITA-TMS-IITA-TMS-IBA011412 and IITA-TMS-IBA011368/IITA-TMS-IBA070337 had the lowest values for DMC and TC, respectively.

Table 4. Mean performance of parents and F1 hybrids for studied characteristics.

\begin{tabular}{|c|c|c|c|c|c|c|}
\hline \multirow{2}{*}{ Genotype } & Trait & RTWT & DMC & FYLD & TC & \multirow{2}{*}{ HI } \\
\hline & RTNO & (kg) & $(\%)$ & $\left(\mathrm{t} \mathrm{ha}^{-1}\right)$ & $\left(\mu g g^{-1}\right)$ & \\
\hline IITA-TMS-IBA011368 & 40.500 & 15.85 & 21.10 & 19.81 & 5.86 & 0.42 \\
\hline IITA-TMS-IBA011371 & 27.25 & 13.70 & 21.04 & 17.13 & 6.66 & 0.48 \\
\hline IITA-TMS-IBA011412 & 36.25 & 24.60 & 15.53 & 30.75 & 6.52 & 0.52 \\
\hline IITA-TMS-IBA070337 & 43.75 & 27.50 & 35.73 & 34.38 & 3.90 & 0.53 \\
\hline IITA-TMS-IBA070553 & 22.00 & 8.75 & 20.89 & 10.94 & 7.96 & 0.41 \\
\hline IITA-TMS-IBA070593 & 34.33 & 19.33 & 24.23 & 24.17 & 9.67 & 0.45 \\
\hline IITA-TMS-IBA011368/IITA-TMS-IBA011371 & 20.19 & 4.91 & 22.84 & 6.14 & 7.59 & 0.25 \\
\hline IITA-TMS-IBA011368/IITA-TMS-IBA011412 & 34.39 & 13.44 & 21.45 & 16.79 & 6.21 & 0.38 \\
\hline IITA-TMS-IBA011368/IITA-TMS-IBA070337 & 39.26 & 16.82 & 24.82 & 21.03 & 4.73 & 0.4 \\
\hline IITA-TMS-IBA011368/IITA-TMS-IBA070553 & 23.94 & 7.67 & 21.8 & 9.59 & 6.98 & 0.26 \\
\hline IITA-TMS-IBA011371/IITA-TMS-IBA011412 & 24.16 & 9.50 & 23.37 & 11.88 & 6.46 & 0.33 \\
\hline IITA-TMS-IBA011371/IITA-TMS-IBA070337 & 34.69 & 15.48 & 28.29 & 19.35 & 5.40 & 0.42 \\
\hline IITA-TMS-IBA011371/IITA-TMS-IBA070553 & 25.80 & 10.26 & 23.24 & 12.82 & 6.08 & 0.32 \\
\hline IITA-TMS-IBA011412/IITA-TMS-IBA070337 & 16.30 & 10.43 & 29.40 & 13.04 & 5.14 & 0.51 \\
\hline IITA-TMS-IBA070553/IITA-TMS-IBA011412 & 28.40 & 9.99 & 18.71 & 12.48 & 7.07 & 0.33 \\
\hline IITA-TMS-IBA070553/IITA-TMS-IBA070337 & 30.12 & 11.09 & 24.76 & 13.86 & 6.10 & 0.33 \\
\hline IITA-TMS-IBA070593/IITA-TMS-IBA011368 & 23.29 & 8.15 & 26.15 & 10.19 & 8.13 & 0.29 \\
\hline IITA-TMS-IBA070593/IITA-TMS-IBA011371 & 22.97 & 8.85 & 23.86 & 11.06 & 7.11 & 0.32 \\
\hline IITA-TMS-IBA070593/IITA-TMS-IBA011412 & 28.27 & 13.6 & 24.89 & 17.00 & 6.69 & 0.38 \\
\hline IITA-TMS-IBA070593/IITA-TMS-IBA070337 & 32.18 & 14.08 & 29.35 & 17.61 & 5.93 & 0.33 \\
\hline IITA-TMS-IBA070593/IITA-TMS-IBA070553 & 26.74 & 10.10 & 24.98 & 12.63 & 6.96 & 0.33 \\
\hline Grand mean & 29.28 & 13.05 & 24.12 & 16.32 & 6.53 & 0.38 \\
\hline $\mathrm{SE} \pm$ & 1.57 & 1.21 & 0.92 & 1.51 & 0.27 & 0.02 \\
\hline
\end{tabular}

RTNO = Root number, RTWT $=$ Root weight, FYLD $=$ Fresh yield, DMC $=$ Dry matter content, $T C=$ Total carotenoids, $\mathrm{HI}=$ Harvest Index, $\mathrm{SE} \pm=$ Standard error. 


\subsection{Combining Ability}

Parent IBA070337 had a highly significant $(p<0.01)$ positive GCA effect for DMC and a significant $(p<0.05)$ negative GCA effect for TC (Table 5). IITA-TMS-IBA011368/IITA-TMS-IBA070337 and IITA-TMS-IBA011371/IITA-TMS-IBA070337 had significant positive SCA effects for FYLD, while IITA-TMS-IBA011368/IITA-TMS-IBA011371 had significant negative SCA effects for FYLD (Table 6). For TC, significant positive SCA effects were exhibited for IITA-TMS-IBA070593/IITA-TMS-IBA011368 while significant but negative SCA effects were also recorded for IITA-TMS-IBA011368/IITA-TMS -IBA070337 for FYLD.

Table 5. Estimates of parental general combining ability effects for fresh yield, dry matter content, and total carotenoids.

\begin{tabular}{|c|c|c|c|c|c|c|c|c|c|c|c|c|}
\hline \multirow{2}{*}{ Parent } & \multirow{2}{*}{$\begin{array}{c}\text { FYLD } \\
\text { Estimate }\end{array}$} & \multirow{2}{*}{$\mathrm{SE} \pm$} & \multirow{2}{*}{$\begin{array}{l}\mathrm{df}=714 \\
t \text { Value }\end{array}$} & \multirow{2}{*}{$\operatorname{Pr}>|t|$} & \multirow{2}{*}{$\begin{array}{c}\text { DMC } \\
\text { Estimate }\end{array}$} & \multirow{2}{*}{$\mathrm{SE} \pm$} & \multirow{2}{*}{$\begin{array}{c}\mathrm{df}=507 \\
t \text { Value }\end{array}$} & \multirow{2}{*}{$\operatorname{Pr}>|t|$} & \multirow{2}{*}{$\begin{array}{c}\text { TC } \\
\text { Estimate }\end{array}$} & \multirow{2}{*}{$\mathrm{SE} \pm$} & \multirow{2}{*}{$\begin{array}{c}\mathrm{df}=721 \\
t \text { Value }\end{array}$} & \multirow{2}{*}{$\operatorname{Pr}>|t|$} \\
\hline & & & & & & & & & & & & \\
\hline IITA-TMS-IBA011368 & -0.35 & 1.09 & -0.33 & 0.745 & -1.16 & 1.04 & -1.11 & 0.267 & 0.28 & 0.34 & 0.82 & 0.415 \\
\hline IITA-TMS-IBA011371 & -0.61 & 1.09 & -0.56 & 0.575 & -0.17 & 1.04 & -0.17 & 0.868 & 0.07 & 0.34 & 0.19 & 0.847 \\
\hline IITA-TMS-IBA011412 & 0.26 & 1.09 & 0.24 & 0.814 & -1.62 & 1.03 & -1.57 & 0.116 & -0.13 & 0.34 & -0.37 & 0.708 \\
\hline IITA-TMS-IBA070337 & 1.36 & 1.09 & 1.25 & 0.212 & $3.23 * *$ & 1.04 & 3.09 & 0.002 & $-0.95 * *$ & 0.34 & -2.79 & 0.005 \\
\hline IITA-TMS-IBA070553 & -0.62 & 1.09 & -0.56 & 0.573 & -1.98 & 1.05 & -1.90 & 0.059 & 0.20 & 0.34 & 0.59 & 0.554 \\
\hline IITA-TMS-IBA070593 & -0.04 & 1.09 & -0.04 & 0.972 & 1.70 & 1.03 & 1.65 & 0.099 & 0.53 & 0.34 & 1.58 & 0.116 \\
\hline
\end{tabular}

\subsection{Estimates of Heterosis}

Estimated values for MPH ranged from $-49.81 \%$ to $30.51 \%$ for FYLD, $-15.1 \%$ to $10.93 \%$ for DMC, and $-19.12 \%$ to $12.79 \%$ for TC while values for BPH ranged from $-58.92 \%$ to $21.67 \%$ for FYLD, $-16.82 \%$ to $7.94 \%$ for DMC, and $-23.74 \%$ to $7.47 \%$ for TC (Table 7). The cross with the best and positive MPH and BPH values for FYLD was IITA-TMS-IBA011368/IITA-TMS-IBA070337, while for DMC it was for IITA-TMS-IBA070593/IITA-TMS-IBA070337. For TC, IITA-TMS-IBA011368/IITA-TMS-IBA011371 and IITA-TMS-IBA011368/IITA-TMS-IBA070553 had the best MPH and BPH, respectively.

\subsection{Estimates of the Phenotypic and Genetic Correlations}

Genetic correlations $\left(\mathrm{r}_{\mathrm{G}}\right)$ were higher than phenotypic correlations for all measured characteristics (Table 8). HI showed a positive and high correlation with the number of roots per plant and FYLD. A negative correlation was observed for DMC and TC with FYLD. 
Table 6. Estimates of specific combining ability effects for fresh yield, dry matter content, and total carotenoids.

\begin{tabular}{|c|c|c|c|c|c|c|c|c|c|c|c|c|}
\hline \multirow{2}{*}{ Cross } & \multirow{2}{*}{$\begin{array}{c}\text { FYLD } \\
\text { Estimate }\end{array}$} & \multirow{2}{*}{$\mathrm{SE} \pm$} & \multicolumn{2}{|c|}{$\mathrm{df}=714$} & \multirow{2}{*}{$\begin{array}{c}\text { DMC } \\
\text { Estimate }\end{array}$} & \multirow{2}{*}{$\mathrm{SE} \pm$} & \multicolumn{2}{|c|}{$\mathrm{df}=507$} & \multirow{2}{*}{$\begin{array}{c}\text { TC } \\
\text { Estimate }\end{array}$} & \multirow{2}{*}{$\mathrm{SE} \pm$} & \multicolumn{2}{|c|}{$\mathrm{df}=721$} \\
\hline & & & $t$ Value & $\operatorname{Pr}>|t|$ & & & $t$ Value & $\operatorname{Pr}>|t|$ & & & $t$ Value & $\operatorname{Pr}>|t|$ \\
\hline IITA-TMS-IBA011368/IITA-TMS-IBA011371 & $-4.75^{*}$ & 2.04 & -2.32 & 0.020 & -0.12 & 0.58 & -0.22 & 0.83 & 0.57 & 0.38 & 1.49 & 0.136 \\
\hline IITA-TMS-IBA011368/IITA-TMS-IBA011412 & 2.72 & 1.74 & 1.57 & 0.118 & -0.15 & 0.55 & -0.27 & 0.79 & -0.33 & 0.35 & -0.93 & 0.354 \\
\hline IITA-TMS-IBA011368/IITA-TMS-IBA070337 & $4.93^{* *}$ & 1.90 & 2.59 & 0.010 & -0.30 & 0.56 & -0.53 & 0.60 & -0.82 & 0.37 & -2.22 & 0.027 \\
\hline IITA-TMS-IBA011368/IITA-TMS-IBA070553 & -2.38 & 2.00 & -1.19 & 0.233 & 0.17 & 0.58 & 0.29 & 0.78 & 0.07 & 0.38 & 0.18 & 0.854 \\
\hline IITA-TMS-IBA011371/IITA-TMS-IBA011412 & -1.33 & 1.79 & -0.74 & 0.459 & 0.04 & 0.56 & 0.06 & 0.95 & 0.07 & 0.36 & 0.20 & 0.839 \\
\hline IITA-TMS-IBA011371/IITA-TMS-IBA070337 & 3.80 & 1.90 & 2.00 & 0.046 & 0.25 & 0.56 & 0.44 & 0.66 & -0.11 & 0.37 & -0.31 & 0.755 \\
\hline IITA-TMS-IBA011371/IITA-TMS-IBA070553 & 0.21 & 1.83 & 0.12 & 0.908 & 0.17 & 0.56 & 0.3 & 0.77 & -0.52 & 0.36 & -1.44 & 0.151 \\
\hline IITA-TMS-IBA011412/IITA-TMS-IBA070337 & -1.69 & 2.04 & -0.83 & 0.409 & 0.38 & 0.58 & 0.65 & 0.52 & -0.16 & 0.38 & -0.42 & 0.674 \\
\hline IITA-TMS-IBA070553/IITA-TMS-IBA011412 & -0.74 & 1.91 & -0.39 & 0.697 & -0.44 & 0.57 & -0.77 & 0.44 & 0.44 & 0.37 & 1.19 & 0.234 \\
\hline IITA-TMS-IBA070553/IITA-TMS-IBA070337 & -0.54 & 1.90 & -0.28 & 0.776 & -0.13 & 0.57 & -0.22 & 0.83 & 0.33 & 0.37 & 0.90 & 0.368 \\
\hline IITA-TMS-IBA070593/IITA-TMS-IBA011368 & -2.73 & 1.79 & -1.53 & 0.127 & 0.31 & 0.56 & 0.56 & 0.58 & $0.74^{* *}$ & 0.36 & 2.09 & 0.037 \\
\hline IITA-TMS-IBA070593/IITA-TMS-IBA011371 & -1.75 & 1.80 & -0.97 & 0.331 & -0.34 & 0.56 & -0.61 & 0.54 & 0.05 & 0.36 & 0.14 & 0.892 \\
\hline IITA-TMS-IBA070593/IITA-TMS-IBA011412 & 2.63 & 1.73 & 1.52 & 0.128 & 0.04 & 0.55 & 0.08 & 0.94 & -0.13 & 0.35 & -0.38 & 0.706 \\
\hline IITA-TMS-IBA070593/IITA-TMS-IBA070337 & 2.00 & 1.88 & 1.06 & 0.288 & 0.06 & 0.56 & 0.1 & 0.92 & -0.06 & 0.36 & -0.150 & 0.880 \\
\hline IITA-TMS-IBA070593/IITA-TMS-IBA070553 & -0.39 & 1.96 & -0.20 & 0.843 & 0.07 & 0.57 & 0.12 & 0.91 & -0.15 & 0.37 & -0.400 & 0.688 \\
\hline
\end{tabular}

$* p<0.05,{ }^{* *} p<0.01$, FYLD $=$ Fresh yield, DMC = Dry matter content, TC $=$ Total carotenoids. 
Table 7. Heterosis (\%) relative to mid parents (MPH) and better parents (BPH) for studied characteristics.

\begin{tabular}{|c|c|c|c|c|c|c|}
\hline \multirow{3}{*}{ Cross } & \multirow{2}{*}{\multicolumn{2}{|c|}{$\begin{array}{c}\text { FYLD } \\
\left(\mathrm{tha}^{-1}\right)\end{array}$}} & \multirow{2}{*}{\multicolumn{2}{|c|}{$\begin{array}{c}\text { DMC } \\
(\%) \\
\end{array}$}} & \multirow{2}{*}{\multicolumn{2}{|c|}{$\begin{array}{c}\text { TC } \\
\left(\mu \mathrm{g} \mathrm{g}^{-1}\right) \text { Fresh Weigh }\end{array}$}} \\
\hline & & & & & & \\
\hline & MPH & BPH & MPH & BPH & MPH & BPH \\
\hline IITA-TMS I011368/IITA-TMS I011371 & -49.81 & -58.92 & -0.91 & -2.95 & 12.79 & 4.58 \\
\hline IITA-TMS I011368/IITA-TMS I011412 & 12.05 & 11.72 & -4.79 & -4.94 & -2.55 & -5.12 \\
\hline IITA-TMS I011368/IITA-TMS I070337 & 30.51 & 21.67 & -0.25 & -8.74 & -19.12 & -23.74 \\
\hline IITA-TMS I011368/IITA-TMS I070553 & -28.62 & -35.83 & -5.28 & -7.06 & 9.35 & 6.25 \\
\hline IITA-TMS I011371/IITA-TMS I011412 & -18.64 & -20.97 & -1.26 & -5.92 & 2.48 & -1.37 \\
\hline IITA-TMS I011371/IITA-TMS I070337 & 23.03 & 11.96 & 8.72 & 4.02 & -6.40 & -10.75 \\
\hline IITA-TMS I011371/IITA-TMS I070553 & -1.73 & -9.53 & -3.75 & -6.45 & -3.65 & -7.45 \\
\hline IITA-TMS I011412/IITA-TMS I070337 & -14.01 & -24.57 & 3.90 & 0.00 & -3.27 & -6.34 \\
\hline IITA-TMS I070553/IITA-TMS I011412 & -11.52 & -16.95 & -15.10 & -16.82 & 7.72 & 7.47 \\
\hline IITA-TMS I070553/IITA-TMS I070337 & -9.05 & -19.83 & 1.50 & -8.96 & 1.06 & -7.28 \\
\hline IITA-TMS I070593/IITA-TMS I011368 & -15.07 & -26.19 & 0.81 & 0.00 & 7.40 & 0.00 \\
\hline IITA-TMS I070593/IITA-TMS I011371 & -5.13 & -19.87 & -3.16 & -7.28 & -0.37 & -2.09 \\
\hline IITA-TMS I070593/IITA-TMS I011412 & 17.92 & 13.11 & 3.21 & -3.27 & -1.30 & -4.55 \\
\hline IITA-TMS I070593/IITA-TMS I070337 & 13.25 & 1.86 & 10.93 & 7.94 & -5.07 & -15.34 \\
\hline IITA-TMS I070593/IITA-TMS I070553 & -1.87 & -8.56 & 1.59 & -2.91 & 2.45 & -0.72 \\
\hline
\end{tabular}

FYLD = Fresh root yield, DMC $=$ Dry matter content, $\mathrm{TC}=$ Total carotenoids.

Table 8. Estimates of phenotypic (upper diagonal) and genetic (lower diagonal) correlations for characteristics evaluated in 21 cassava genotypes.

\begin{tabular}{ccccccc}
\hline & DMC & TC & FYLD & HI & RTNO & CMD \\
\hline DMC & - & 0.08 & $0.07^{* * *}$ & $0.15^{* * *}$ & 0.04 & -0.06 \\
TC & $-0.17^{* * *}$ & - & $-0.16^{* * *}$ & $-0.14^{* * *}$ & $-0.12^{* * *}$ & -0.07 \\
FYLD & $0.16^{* * *}$ & $-0.29^{* * *}$ & - & $0.69^{* * *}$ & $0.74^{* * *}$ & $-0.45^{* * *}$ \\
HI & $0.17^{* * *}$ & $-0.30^{* * *}$ & $0.80^{* * *}$ & - & $0.47^{* * *}$ & $-0.34^{* * *}$ \\
RTNO & 0.01 & $-0.26^{* * *}$ & $0.94^{* * *}$ & $0.63^{* * *}$ & - & $-0.46^{* * *}$ \\
CMD & -0.03 & $-0.08^{*}$ & $-0.63^{* * *}$ & $-0.44^{* * *}$ & $-0.61^{* * *}$ & - \\
\hline
\end{tabular}

* $p<0.05,{ }^{* * *} p<0.001, \mathrm{DMC}=$ Dry matter content, TC $=$ Total carotenoids, RTNO = Root number, FYLD = Fresh yield, $\mathrm{HI}=$ Harvest Index, $\mathrm{RTNO}=$ root number, $\mathrm{CMD}=$ cassava mosaic disease.

\subsection{Estimates of Variance Components, Broad and Narrow Sense Heritability, and Genetic Advance}

FYLD, DMC, TC, and cassava mosaic disease (CMD) exhibited high genotypic $\left(\sigma^{2}{ }_{G}\right)$ and phenotypic $\left(\sigma^{2} \mathrm{P}\right)$ variances (Table 9$)$. The genotypic variance was separated into the additive $\left(\sigma^{2} \mathrm{~A}\right)$ and non-additive/dominance $\left(\sigma^{2} \mathrm{D}\right)$ variance components. Additive variance $\left(\sigma^{2} \mathrm{~A}\right)$ values were higher for DMC, TCC, and CMD than their corresponding non-additive variance $\left(\sigma^{2}{ }_{D}\right)$ except for FYLD, where the non-additive variance was higher than its corresponding additive variance. The difference between the $\sigma^{2}{ }_{G}$ and $\sigma^{2}{ }_{P}$ was high for all the characteristics evaluated except for CMD. High genotypic (GCV) and phenotypic (PCV) coefficient of variances were observed for all characteristics except for DMC, which recorded high PCV but average GCV (Table 9). Phenotypic coefficient of variability (PCV) values ranged from $31.24 \%$ for TC to $69.24 \%$ for FYLD, while the genotypic coefficient of variability (GCV) ranged from $18.50 \%$ for DMC to $42.39 \%$ for FYLD. PCV values were generally higher than their corresponding GCV values for all the characteristics considered. Broad sense heritability $\left(\mathrm{h}^{2} \mathrm{~b}\right)$ was higher than the corresponding narrow sense heritability $\left(\mathrm{h}^{2}{ }_{\mathrm{n}}\right)$ for all the characteristics. Estimated values of $\mathrm{h}^{2} \mathrm{~b}$ values ranged from $22.58 \%$ for CMD to $60.58 \%$ TC whereas the $\mathrm{h}^{2}{ }_{\mathrm{n}}$ ranged from $5.18 \%$ for FYLD to $37.49 \%$ for DMC. Genetic advance as a percentage of the mean was high $(>20)$ for all the studied characteristics. This ranged from 24.58 for CMD severity to 53.59 for FYLD. 
Table 9. Estimates of genetic variance components, heritability (\%), and genetic advance (\%) of the studied characteristics in yellow cassava genotypes.

\begin{tabular}{|c|c|c|c|c|c|c|c|c|c|c|c|}
\hline \multirow{2}{*}{ Trait } & \multirow{2}{*}{ Mean } & \multicolumn{7}{|c|}{ Variance Components } & \multicolumn{3}{|c|}{ Genetic Advance } \\
\hline & & $\sigma_{\mathrm{A}}^{2}$ & $\sigma^{2} D$ & $\sigma_{\mathrm{e}}^{2}$ & $\sigma^{2} P$ & PCV (\%) & GCV (\%) & $h_{b}^{2}(\%)$ & $h_{n}^{2}(\%)$ & GA & GAM (\%) \\
\hline FYLD & 16.32 & 6.61 & 41.26 & 113.96 & 127.58 & 69.24 & 42.39 & 37.52 & 5.18 & 8.75 & 53.59 \\
\hline DMC & 24.12 & 18.44 & 1.48 & 39.60 & 49.19 & 29.06 & 18.50 & 40.50 & 37.49 & 5.86 & 24.30 \\
\hline $\mathrm{TC}$ & 6.53 & 1.36 & 1.16 & 3.19 & 4.16 & 31.24 & 24.31 & 60.58 & 32.69 & 2.55 & 39.05 \\
\hline CMD & 2.11 & 0.20 & 0.08 & 1.12 & 1.24 & 57.76 & 25.08 & 22.58 & 16.13 & 0.52 & 24.58 \\
\hline
\end{tabular}

$\sigma^{2} \mathrm{~A}=$ Additive genetic variance, $\sigma^{2} \mathrm{D}=$ Dominance genetic variance, $\sigma^{2}{ }_{\mathrm{e}}=$ Environmental variance, $\sigma^{2} \mathrm{P}=$ Phenotypic variance, $\mathrm{PCV}=$ Phenotypic coefficient of variation, $\mathrm{GCV}=$ Genotypic coefficient of variation, $\mathrm{h}^{2}{ }_{\mathrm{b}}=$ Broad-sense heritability, $\mathrm{h}^{2}{ }_{\mathrm{n}}=$ Narrow-sense heritability, GA = Genetic advance and GAM = Genetic advance as percent of mean .

\section{Discussion}

The mean performance of the clones within each family showed significant variations. This confirmed the possibility of selection for these characteristics through hybridization of respective parents. A similar trend was reported previously [13,14]. The significant variation in values observed for the genotypes for the different characteristics (Table 4) indicate the presence of genetic variability among the genotypes. High genetic variability for different characteristics has also been reported in other studies $[8,13]$. The significant estimates of SCA mean squares for FYLD and TC presented in this study indicates that non-additive gene effects are more important than additive gene effects in the control of these characteristics. The significant SCA effects for FYLD observed in this study agreed with previous findings $[9,13]$ while that of TC was in agreement with a previous study [3]. Higher values than unity for the GCA/SCA ratio for DMC and TC is an indication that the additive gene effects make a larger contribution in the control of DMC and TC than non-additive effects, while for FYLD, the non-additive gene effects predominated. Similarly, a Baker's ratio close to one for DMC and TC is an indication that progeny performance is based on GCA [16]. Nonetheless, the predicted GCA/SCA ratio and Baker's prediction ratio may not always project the true picture of the gene action for a trait due to the differential parental ability to combine well. The performance of the crosses with respect to the parental genotypes suggests that progeny performance cannot be predicted from the performance of the parents per se. Performance also depends upon the complex interaction between the genotype and environment $[9,16]$.

GCA and SCA effects show both the magnitude and direction of genetic effects. The significant positive and negative GCA effects recorded for parent IBA070337 for DMC and TC, respectively, indicate that the genotype contributed highly to DMC but very little to TC. Thus, this genotype was the most superior and best general combiner for DMC but a poor combiner for TC. For the cross progenies, the significant positive SCA effects obtained for IITA-TMS-IBA011368/IITA-TMS-IBA070337 and IITA-TMS-IBA070593/IITA-TMS-IBA011368 for FYLD and TC, respectively, indicate that these cross progenies are the best specific combiners for these characteristics. More than one-third of the cross progenies showed desirable positive (though not significant) SCA effects for DMC. This suggests average SCA for DMC. SCA of contrasting parent genotypes used for genetic improvement of a trait can transmit the desirable specific trait to the next generation [10].

There was good mid and better parent heterosis for the studied characteristics in some of the cross progenies. This may indicate that additive and non-additive genetic effects in the crosses are acting in the same direction. It also suggests that these cross progenies can be exploited in heterosis breeding to develop superior genotypes to take full advantage of these specific characteristics. Heterosis over mid and better parents were previously reported for cassava characteristics, which varied according to the cross combinations and measured characteristics, and it played a very important role in cassava performance $[9,12,14]$.

Phenotypic correlation is the correlation of the genotype means for characteristics and this is partitioned into genetic and environmental sources. However, genetic correlation is heritable and of more practical importance. Higher genetic than the phenotypic correlations observed for all evaluated 
characteristics is an indication that genetic factors were major contributors to correlations among characteristics, and this is favorable for the selection process. Positive correlation between the harvest index and number of roots per plant $\left(\mathrm{r}_{\mathrm{G}}=0.63\right)$ and FYLD $\left(\mathrm{r}_{\mathrm{G}}=0.80\right)$ is an indication that the increase of one trait will simultaneously increase the other. These results agree with previous findings [6], where positive and high genetic correlations between tuberous root yield and shoot biomass yield were reported. The presence of a positive correlation may indicate a balance in the source sink relationship. Negative correlations of TC with DMC and FYLD were observed in this study as was previously reported [33,34], where an inverse relationship of $\beta$-carotene content with DMC as well as FYLD was seen.

The higher phenotypic coefficient of variance than the genotypic coefficient of variance observed for all characteristics agrees with a previous study [31]. Considering the benchmark for broad sense heritability ( $0-30 \%$ as low, $30-60 \%$ as moderate, and $60 \%$ and above as high), $\mathrm{h}^{2}{ }_{\mathrm{b}}$ for CMD severity was low $(22.58 \%)$, moderate for FYLD (37.52\%) and DMC (40.5\%), and high for TC (60.58\%). The relatively high estimates of broad sense heritability observed for FYLD, DMC, and TC gives an indication that these characteristics are primarily under genetic control. Selection for these characteristics should lead to genetic advance [18]. High heritability of a characteristic makes selection more effective. High heritability $(>30)$ coupled with high genetic advance $(>20)$ as a percent of the mean for FYLD, DMC, and TC gives an indication that selection for genetic improvement of cassava is reliable. High heritability with high genetic advance as a percentage of the mean for plant height and root fresh weight in cassava was previously reported [35].

\section{Conclusions}

The role of additive and non-additive gene action in the determination and control of FYLD, DMC and TC presented in this study suggests the possibility of effective selection for genetic improvement of cassava as applicable mainly to the genetic makeup of the parents presented. Families from crosses among elite cassava clones were very promising for genetic improvement for multiple important characteristics, taking full advantage of genetic variance inherent in cassava clones for high yield potential. High heritability $(>30)$ with high genetic advance $(>20)$ is important for selection and the genetic improvement of cassava. It is therefore necessary to conduct further studies with the test genotypes in bigger trials and in several locations and seasons to confirm the results presented in this study.

Author Contributions: Conceptualization, E.P. and P.K.; methodology, O.A., P.A., A.A. and P.I.; formal analysis, M.B.; investigation, A.K.; writing—original draft preparation, A.K.; writing—review and editing, M.L.; supervision, E.P. and P.A.; funding acquisition, P.K. All authors have read and agreed to the published version of the manuscript.

Funding: This research was funded by HarvestPlus (grant number 306053.006.007) and Bill and Melinda Gates Foundation.

Acknowledgments: The research was supported by the cassava breeding unit of the International Institute of Tropical Agriculture, Ibadan.

Conflicts of Interest: The authors declare no conflict of interest. The funders had no role in the design of the study; in the collection, analyses, or interpretation of data; in the writing of the manuscript, or in the decision to publish the results.

\section{References}

1. Mehari, G.; Amsalu, N.; Tewodros, M. Estimates of genetic components for yield and quality of cassava (Manihot esculenta Crantz) genotypes at Jimma, South west Ethiopa. Int. J. Plant Breed. Genet. 2015, 9, 1-12.

2. El-Sharkawy, M.A. Physiological characteristics of cassava tolerance to prolonged drought in the tropics: Implications for breeding cultivars adapted to seasonally dry and semiarid environments. Braz. J. Plant Physiol. 2007, 19, 257-286. [CrossRef]

3. Njenga, P.; Edema, R.; Kamau, J. Combining ability for beta-carotene and important quantitative traits in a cassava f1 population. J. Plant Breed. Crop Sci. 2014, 6, 24-30. [CrossRef] 
4. Kawano, K. Cassava. In Hybridisation of Crop Plants; Walter, R., Ed.; America Society of Agronomy and Crop Science Society of America: Madison, WI, USA, 1980; pp. 225-233.

5. Ntawuruhunga, P.; Ssemakula, G.; Ojulong, H.; Bua, A.; Ragama, P.; Kanobe, C.; White, J. Evaluation of advanced genotypes in Uganda. Afr. Crop Sci. J. 2006, 14, 17-25.

6. Ntawuruhunga, P.; Dixon, A.G.O. Quantitative variation and interrelationship between factors influencing cassava yield. J. Appl. Biosci. 2010, 26, 1594-1602.

7. United Nations Children's Fund (UNICEF). Vitamin A Supplementation: A Statistical Snapshot. Harnessing the Power of Two Life Giving Drops; UNICEF: New York, NY, USA, 2016.

8. Kawano, K.; Fukuda, W.M.G.; Cenpukdee, U. Genetic and environmental effects on dry matter content of cassava root. Crop Sci. 1987, 27, 69-74. [CrossRef]

9. Calle, F.; Perez, J.C.; Gaitán, W.; Morante, N.; Ceballos, H.; Llano, G.; Álvarez, E. Diallel inheritance of relevant traits in cassava (Manihot esculenta Crantz) adapted to acid-soil savannas. Euphytica 2005, 144, 177-186. [CrossRef]

10. Cach, T.N.; Lenis, J.I.; Pérez, J.C.; Morante, N.; Calle, F.; Ceballos, H. Inheritance of relevant traits in cassava (Manihot esculenta Crantz) for sub-humid conditions. Plant Breed. 2006, 125, 177-182. [CrossRef]

11. Jaramillo, G.; Morante, N.; Perez, J.C.; Calle, F.; Ceballos, H.; Arias, B.; Bellotti, A.C. Diallel analysis in cassava adapted to the midaltitude valleys environment. Crop Sci. 2005, 45, 1058-1063. [CrossRef]

12. Kulembeka, H.P.; Ferguson, M.; Herselman, L.; Kanju, E.; Mkamilo, G.; Masumba, E.; Fregene, M.; Labuschagne, M.T. Diallel analysis of field resistance to brown streak disease in cassava (Manihot esculenta Crantz) landraces from Tanzania. Euphytica 2012, 187, 277-288. [CrossRef]

13. Chipeta, M.M.; Bokosi, J.M.; Saka, V.W. Genetic analyses in a six parent diallel cross of cassava (Manihot esculenta Crantz). Afr. J. Agric. Res. 2015, 10, 1076-1082.

14. Tumuhimbise, R.; Melis, R.; Shanahan, P. Diallel analysis of early storage root yield and disease resistance traits in cassava (Manihot esculenta Crantz). Field Crops Res. 2014, 167, 86-93. [CrossRef]

15. Unikrishnan, M.; Easwari, C.S.; Santha, V.; Pillai Sheela, M.N.; Anantharaman, M.; Nair, N.N. Varietal Improvement Programme in Cassava; Annual report 2002-2003; CTCRI: Thiruvananthapuram, India, 2004.

16. Falconer, D.S.; Mackay, T.F.C. Introduction to Quantitative Genetics, 4th ed.; Longman: New York, NY, USA, 1996.

17. Mohsin, T.; Khan, N.; Naqvi, F.N. Heritability, phenotypic correlation and path coefficient studies for some agronomic characters in synthetic elite lines of wheat. J. Food Agric. Environ. 2009, 7, 278-282.

18. Singh, B.D. Plant Breeding: Principles and Methods; Kalyani Publishers: New Delhi, India, 2001.

19. Johnson, G.R.; King, J.N. Analysis of half diallel mating designs I-A practical analysis procedure for ANOVA approximation. Silvae Genet. 1998, 47, 74-79.

20. Larik, A.S.; Malik, S.I.; Kakar, A.A.; Naz, M.A. Assesment of heritability and genetic advance for yield and yield components in Gossypium hirsutum L. Sci. Khyber 2000, 13, 39-44.

21. Fukuda, W.M.G.; Guevara, C.L.; Kawuki, R.; Ferguson, M.E. Selected Morphological and Agronomic Descriptors for the Characterization of Cassava; International Institute of Tropical Agriculture (IITA): Ibadan, Nigeria, 2010.

22. Jaramillo, A.M.; Londoño, L.F.; Orozco, J.C.; Patiño, G.; Belalcazar, J.; Davrieux, F.; Talsma, E.F. A comparison study of five different methods to measure carotenoids in biofortified yellow cassava (Manihot esculenta). PLoS ONE 2018, 13, e0209702. [CrossRef]

23. Statistical Analysis System (SAS) Institute Incorporate. Statistical Analysis System; Software Version 9.3; SAS: Cary, NC, USA, 2011.

24. Griffing, B. Concept of general and specific combining ability in relation to diallel crossing systems. Aust. J. Biol. Sci. 1956, 9, 463-493. [CrossRef]

25. Piepho, H.-P.; Möhring, J.; Melchinger, A.E.; Büchse, A. BLUP for phenotypic selection in plant breeding and variety testing. Euphytica 2008, 161, 209-228. [CrossRef]

26. Parkes, E.Y.; Fregene, M.; Dixon, A.; Boakye-Peprah, B.; Labuschagne, M.T. Combining ability of cassava genotypes for cassava mosaic disease and cassava bacterial blight, yield and its related components in two ecological zones in Ghana. Euphytica 2013, 194, 13-24. [CrossRef]

27. Baker, R.J. Issues in diallel analysis. Crop Sci. 1978, 18, 533-536. [CrossRef]

28. Dar, Z.A.; Wani, S.A.; Wani, M.A.; Gulzaffar, M.; Khan, H.; Habib, M.; Ahmed, Z.; Ishfaque, A. Heterosis and combining ability analysis for seed yield and its attributes in Brassica rapa ssp. brown sarson. J. Oilseed Brassica 2011, 2, 21-28. 
29. Singh, R.K.; Chaudhury, B.D. Biometrical Methods in Quantitative Genetic Analysis; Kalyani Publishers: New Delhi, India, 1985.

30. Deshmukh, S.N.; Basu, M.S.; Reddy, P.S. Genetic variability, character association and path coefficient analysis of quantitative traits in Virginia bunch varieties of groundnut. Indian J. Agric. Sci. 1986, 56, 816-821.

31. Shukla, S.; Bhargava, A.; Chatterjee, A.; Srivastava, J.; Singh, N.; Singh, S.P. Mineral profile and variability in vegetable amaranth (Amaranthus tricolor). Plant Foods Hum. Nutr. 2006, 61, 21-26. [CrossRef] [PubMed]

32. Akinwale, M.G.; Aladesanwa, R.D.; Akinyele, B.O.; Dixon, A.G.O.; Odiyi, A.C. Inheritance of ß-carotene in cassava (Manihot esculenta Crantz). Int. J. Genet. Mol. Biol. 2010, 2, 198-201.

33. Vimala, B.; Nambisan, B.; Theshara, R.; Unnikrishnan, M. Variability of carotenoids in yellow-flesh cassava (Manihot esculenta Crantz) clones. Gene Conserve 2009, 31, 676-685.

34. Tewodros, M.; Yared, D. Nature of gene action in elite cassava genotypes (Manihot esculenta Crantz) in South Ethiopia. Sky J. Agric. Res. 2014, 3, 67-73.

35. Kashiani, P.; Saleh, G. Estimation of genetic correlations on sweet corn inbred lines using SAS mixed model. Am. J. Agric. Biol. Sci. 2010, 5, 309-314. [CrossRef]

Publisher's Note: MDPI stays neutral with regard to jurisdictional claims in published maps and institutional affiliations.

(C) 2020 by the authors. Licensee MDPI, Basel, Switzerland. This article is an open access article distributed under the terms and conditions of the Creative Commons Attribution (CC BY) license (http://creativecommons.org/licenses/by/4.0/). 